\title{
Formation and stability of poly-L-lysine/casein multilayers
}

\author{
Lilianna Szyk-Warszyńska • Joanna Piekoszewska • \\ Piotr Warszyński
}

Received: 8 March 2010 / Accepted: 4 May 2010 / Published online: 22 June 2010

(c) The Author(s) 2010. This article is published with open access at Springerlink.com

\begin{abstract}
The aim of our work was to investigate formation of multilayer films containing biocompatible polycation poly-L-lysine (PLL) and $\alpha$ - or $\beta$-casein. Since in the neutral $\mathrm{pH}$ casein is negatively charged, it has been used as a polyanionic layer for the film build-up. Casein containing films were formed at surface of $\mathrm{Si} / \mathrm{SiO}_{2}$ wafers and their thickness was measured by ellipsometry. The effect of ionic strength of PLL and casein solutions was investigated. After the multilayer films were formed, they were contacted with solutions having various $\mathrm{pH}$ and salts to determine film stability under these conditions. Additionally the response of the thickness of PLL/casein films to the temperature variation in the range of $5-45{ }^{\circ} \mathrm{C}$ was also analyzed. Formation and stability of casein containing films was also investigated on surfaces of titanium and stainless steel. We used fluorescently labeled protein to monitor the amount of casein in the film and its change after treatment with solutions containing calcium ions.
\end{abstract}

Keywords Casein - Layer-by-layer · Polyelectrolyte films . Stability $\cdot$ Multilayers

\section{Introduction}

Casein belongs to the class of Intrinsically Unstructured Proteins (IUP), i.e., proteins that in their natural state do not adopt stable, folded structures (Dyson and Wright 2002; Tompa 2002; Wright and Dyson 1999; Brighta et al. 2001). A characteristic feature of these proteins is an open structure, which becomes preserved even after ligand binding.

L. Szyk-Warszyńska $(\bowtie) \cdot$ J. Piekoszewska · P. Warszyński Institute of Catalysis and Surface Chemistry, Polish Academy of Sciences, Krakow, Poland

e-mail:ncszyk@cyf-kr.edu.pl
They are abundant in nature and play an important role in living organisms. Casein is one of the most common IUPs, a phosphoprotein present in mammalian milk and its products, where it occurs as micelles made of four major components (Qi et al. 2004; Swaisgood 1992; Alaimo et al. 1999): $\alpha_{\mathrm{s}^{-}}, \alpha_{\mathrm{s} 2^{-}}, \beta-, \kappa$-casein. $\alpha_{\mathrm{s} 1^{-}}$and $\alpha_{\mathrm{s} 2}$-caseins comprise $40 \%$ and $10 \%$ respectively of the whole casein content of milk and are usually called $\alpha_{\mathrm{s}}$-caseins. $\beta$-casein comprises $38 \%$ of total casein contents. The function of these caseins is to store and transport bio-available metal ions (especially $\mathrm{Ca}(\mathrm{II})$ and $\mathrm{Mg}(\mathrm{II})$ ) by sequestering and transporting them from mother to the neonate (Alaimo et al. 1999; Smyth et al. 2004; Horne 2002). The function of $\kappa$-casein is to stabilize casein micelles (Horne 2002).

In aqueous solutions casein is surface active (Horne 2002; Maldonado-Valderrama et al. 2004; Miller et al. 2004; Maldonado-Valderrama et al. 2008) and forms micellar aggregates. However, a single protein behaves as a flexible, disordered, polyelectrolyte-like molecule (Maheshwari et al. 2006) and can be integrated into a structure of polyelectrolyte films (Szyk-Warszyńska et al. 2009). The casein's ability to bind calcium ions makes it an interesting material for biotechnology and biomedical applications. For instance, the surface of materials for dental implants can be modified by films containing calcium crystallites, which provide better osteointegration of implants (FurediMilhofer et al. 2004). Caseins are used in water based paints or as adhesives for labeling glass containers (MullerBuschbaum et al. 2006). Materials covered with casein containing films can also be applied in the dairy industry for the control of calcium deposit formation. Casein can also be used in biosorbents for removal of multivalent metal ions (zinc, cadmium, mercury, chromium) (Mishra et al. 1998; Seki and Suzuki 2002). 
Sequential adsorption of charged nanoobjects at interfaces is a very versatile technique to form nanostructured thin films. In particular, the sequential adsorption of polyelectrolytes, also referred to as layer-by-layer adsorption technique, which was introduced by Decher et al. (1991, 1997), has attracted much attention in the recent years. It allows to produce multilayer films with well-defined thickness and surface properties. The layer-by-layer technique can be useful in a wide range of applications (Castelnovo and Joanny 2000; Hammond 2000; Schönhoff 2003). Embedding of proteins or other bioactive nanoparticles in polyelectrolyte multilayer films can contribute to formation of surface nanostructures, which can be used in a biomaterial area (Tang et al. 2006).

In our previous work we demonstrated that polyelectrolyte films containing casein can be formed at the surface of silicon wafers and casein embedded in such films preserved its ability to bind calcium ions from calcium chloride solutions (Szyk-Warszyńska et al. 2009). In this paper we concentrated on the formation of polyelectrolyte multilayer films containing $\alpha$ - and $\beta$-casein with biocompatible polyL-lysine used as a polycation. Films were constructed at the surface of silicon wafers, stainless steel and titanium plates and then exposed to the solutions of various composition to determine their stability.

\section{Materials and methods}

$\alpha$-casein (Cat. No. C6780-1G, min 70\%, $\alpha$-cas) and $\beta$-casein (Cat. No. C6905-1G, min 90\%, $\beta$-cas) from bovine milk, poly-L-lysine hydrochloride (PLL), MW 3000070 000, (Cat. No. P-2636), HEPES (N-2-Hydroxyethylpiperazine-N'-2-ethanesulfonic acid, Cat. No. H6147), calcium chloride and calcium phosphate were obtained from Sigma. Sodium chloride pure p.a., hydrochloric acid, sodium hydroxide, sulfuric acid and hydrogen peroxide were obtained from POCh, Poland. Fluorescent labeled casein (casein fluorescein conjugate-CAS ${ }^{*}$ ), being a mixture of different casein forms, was obtained from Invitrogen (Cat. No. C2990).

Polished silicon wafers were purchased from On Semiconductor Czech Republic, a.s. (Cz/100T-0.5mm/(100)/ P Type). Stainless steel (316L) plates and titanium plates were cut from the rods purchased from Goodfellow Inc and polished.

The thickness of PLL/casein multilayer films adsorbed on silicon wafers was measured by imaging ellipsometer $\mathrm{EP}^{3}$ (Nanofilm). By fitting the optical model to the measured values of $\Psi$ and $\Delta$, thickness and optical properties (refractive index, absorbance) of films adsorbed at surface were calculated (Keddie 2001). For the ellipsometric measurements the multilayer films were deposited on silicon wafers $\mathrm{Si} / \mathrm{SiO}_{2}$ by the layer-by layer adsorption of PLL and casein. Before using them as support for the films, wafers were washed in piranha solution $\left(\mathrm{H}_{2} \mathrm{SO}_{4}: \mathrm{H}_{2} \mathrm{O}_{2}, 1: 1\right)$, boiled three times in distilled water and rinsed with an excess of distilled water. In such a way, on the top of silicon wafer, an uniform silica layer was formed. Its thickness was established by ellipsometry multi-angle analysis and was equal to $3 \pm 1 \mathrm{~nm}$. The refractive index of PLL/casein film was found 1.55 using the same method. For the film thickness determination the two layer $\left(\mathrm{SiO}_{2} /\right.$ film) constant, $n, k$ model was used (Tompkins and Irene 1999).

To establish the dependence of thickness of casein containing multilayer on the ionic strength of PLL and casein solutions, films were formed from their aqueous solutions with addition of $\mathrm{NaCl}$. After formation of the film the wafers were carefully dried in a stream of nitrogen at room temperature to remove the water layer from the surface and to avoid dust contamination. Further details concerning the method of multilayer films formation and measurements of their thickness can be found elsewhere (Szyk-Warszyńska et al. 2009).

To determine stability of multilayer films polycation layer was formed using $0.1 \mathrm{~g} / \mathrm{cm}^{3}$ PLL solution in HEPES $(10 \mathrm{mM}, 0.15 \mathrm{M} \mathrm{NaCl}, \mathrm{pH} 7)$, while negatively charged $\alpha$ - or $\beta$-casein layers were adsorbed from $0.1 \mathrm{~g} / \mathrm{dm}^{3}$ solution in HEPES buffer $(10 \mathrm{mM}, 0.15 \mathrm{M} \mathrm{NaCl}, \mathrm{pH}$ 7). Washing steps were performed using HEPES as well. Then, the $\mathrm{Si} / \mathrm{SiO}_{2}$ plates with films: (PLL/ $\alpha$ - or $\beta$-casein) $)_{n}$ or (PLL $/ \alpha$ - or $\beta$-casein $)_{n}$ PLL were immersed in solutions of calcium chloride $\left(c_{\mathrm{CaCl} 2}=0.15 \mathrm{M}, 0.15 \mathrm{M} \mathrm{NaCl}\right)$, calcium phosphate $\left(c_{\mathrm{Ca} 3(\mathrm{PO} 4) 2}=0.15 \mathrm{M}, 0.15 \mathrm{M} \mathrm{NaCl}\right)$, HEPES $(10 \mathrm{mM})$ or in solutions of various $\mathrm{pH}$ values $(2,4,9,7.4$ and 11 regulated by addition of $\mathrm{HCl}$ and $\mathrm{NaOH}$ ) for 24 hours. After that the plates were washed with distilled water, dried and analyzed by the ellipsometer.

The PLL/casein films were also formed on stainless steel and titanium plates, but instead of $\alpha$ - or $\beta$-casein the fluorescent labeled casein, CAS ${ }^{*}\left(0.1 \mathrm{~g} / \mathrm{dm}^{3}\right.$ in HEPES $)$ was used. Before build up of the multilayer films, stainless steel plates were washed in piranha solution and rinsed with distilled water. The titanium plates were washed in detergent solution, rinsed with water, then washed with ethanol and at the end again rinsed with distilled water.

The PLL/CAS* multilayer films were also deposited at surface of silicon wafers and contacted with the solutions of $\mathrm{Ca}_{3}\left(\mathrm{PO}_{4}\right)_{2}\left(c_{\mathrm{Ca} 3(\mathrm{PO} 4) 2}=0.15 \mathrm{M}, 0.15 \mathrm{M} \mathrm{NaCl}\right)$ and $\mathrm{CaCl}_{2}$ $\left(c_{\mathrm{CaCl} 2}=0.15 \mathrm{M}, 0.15 \mathrm{M} \mathrm{NaCl}\right)$ and after drying, changes of film thickness and fluorescence intensity were monitored.

The thickness of (PLL/casein) films was analyzed in dependence on temperature. The methodology of the experiment was as follows. Films were formed, layer-by-layer, at the surface of silicon wafers from the solutions of PLL 

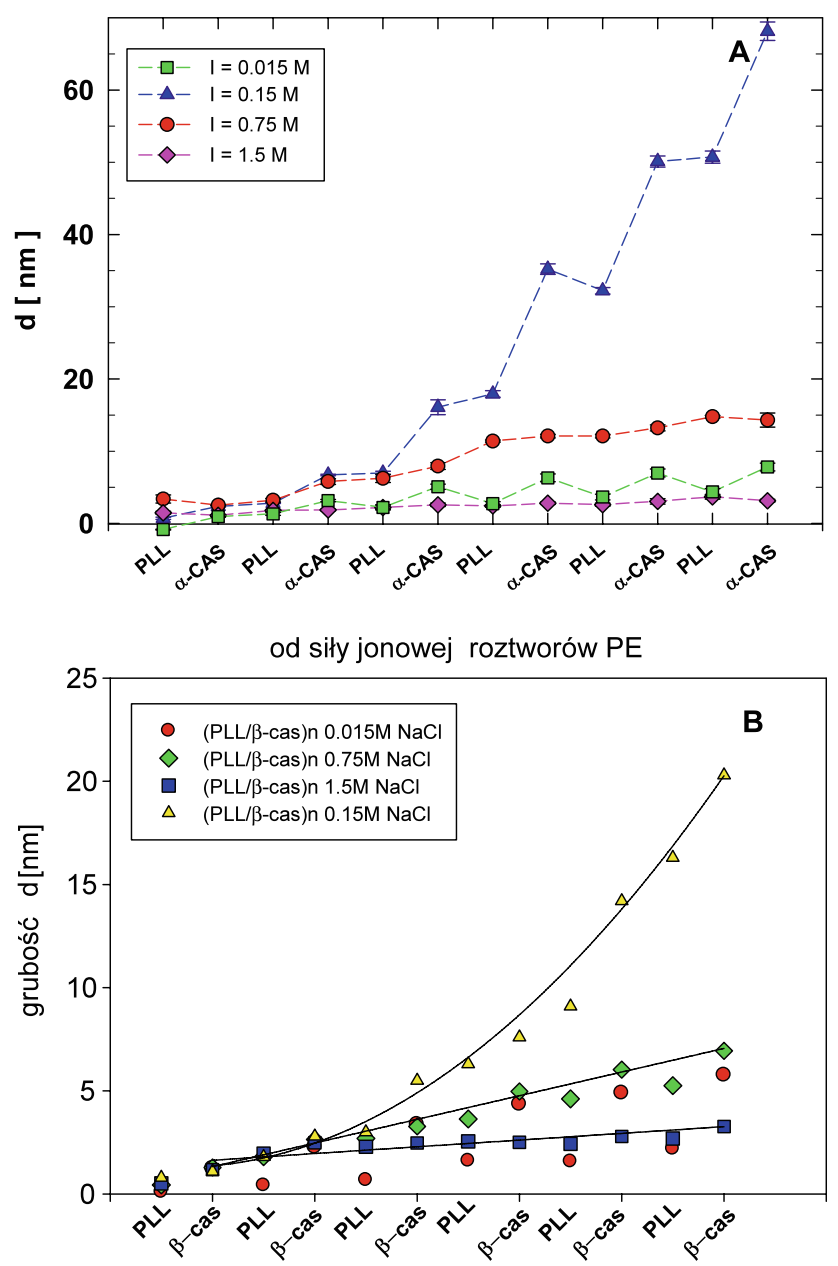

Fig. 1 Dependence of the ellipsometric thickness of (PLL/casein $)_{n}$ multilayer films formed from solutions of various $\mathrm{NaCl}$ concentrations on the number of deposited, successive PLL and casein layers; (A) $\alpha$-casein, (B) $\beta$-casein. Lines are drawn to guide an eye

and casein in HEPES (10 mM, $0.15 \mathrm{M} \mathrm{NaCl}, \mathrm{pH} 7)$. Wafers with films were dried and placed in the ellipsometer on top of Peltier element and their initial thickness at temperature $20^{\circ} \mathrm{C}$ was measured. Then, the temperature was increased stepwise by $5^{\circ} \mathrm{C}$ steps. After the time necessary for equilibration of temperature ( 15 minutes), the thickness of multilayer films was measured. The procedure was repeated until temperature reached $45^{\circ} \mathrm{C}$. Afterwards the temperature changes were reversed and the wafer with the film was cooled stepwise down to $5^{\circ} \mathrm{C}$ and heated again to $45^{\circ} \mathrm{C}$.

\section{Results and discussion}

Figure 1 presents the dependence of the ellipsometric thickness of (PLL/casein $)_{n}$ multilayers formed from the solution of polycation and casein with various $\mathrm{NaCl}$ concentrations.
It can be seen that the optimal ionic strength for the formation of the multilayer is $I=0.15 \mathrm{M} \mathrm{NaCl}$. Formation of the film is electrostatically driven. For lower salt concentration, due to electrostatic repulsion, polyelectrolytes (especially linear PLL) assume stretched conformations. Moreover, lateral electric interactions between adsorbing polyelectrolyte (or protein) molecules during layer formation are strongly repulsive. Both these effects lead to build-up of thinner layers. On the other hand at high ionic strength the electric interactions between adsorbing polycation and casein in the top layer (or vice versa) are screened, so the multilayers cannot be effectively formed. Growth of the film thickness is not uniform. One can observe that the increase of film thickness is much higher in the case of casein adsorption than during formation of the PLL layer. It can be explained by the difference of the cross-section of casein (7.5-9 nm) and PLL molecule (1-2 nm). Moreover, also aggregates of casein can be deposited during film formation. The increase of the thickness for the film with up to 4-6 layers is smaller than for one with larger number of layers already deposited. It is a common feature observed during formation of polyelectrolyte films, connected with the build-up of precursor layers of the film, which are adjacent to the silicon surface (Buron et al. 2006; Kolasińska et al. 2007). For some conditions of the film formation one can also observe non-monotonous growth of its thickness with the number of deposited layer. This feature is characteristic for the formation of films consisting of weak polyelectrolytes (Elzbieciak et al. 2009) and is caused by formation of surface polycation/polyanion complexes, which can be removed during next deposition step. One can notice that multilayers containing $\alpha$-casein are much thicker than ones with $\beta$-casein, which can be explained by more flexible structure of $\alpha$-casein (Horne 2002) and possibility of formation of larger aggregates.

To determine the stability of the casein containing films, they were formed in the optimal conditions, i.e. the ionic strength of the casein and PLL solution was equal to $I=$ $0.15 \mathrm{M} \mathrm{NaCl}$ (in HEPES) and the films were exposed for 24 hours to the solutions of various $\mathrm{pH}$. The results of such experiment are collected in Table 1 . It can be seen that under strong acid conditions ( $\mathrm{pH}$ 2) films are not stable due to positive charge of both, casein (Szyk-Warszyńska et al. 2009) and silicon wafer (Kosmulski 2001). Therefore, in $\mathrm{pH} 2$, there are no electrostatic interactions keeping together PLL and casein in the film. In the strongly basic conditions (pH 11) multilayer films are also unstable due to low charge of poly-L-lysine, which is a weak polycation. In weakly acidic conditions ( $\mathrm{pH} \mathrm{4)} \alpha$-casein containing films seem to be stable. Although in these conditions protein molecule possesses net low positive charge (Szyk-Warszyńska et al. 2009), it also contains some negative regions and that, combining with hydrophobic interactions (Dickinson 2006), 
Table 1 Ellipsometric thickness (in nanometers) of multilayer films (PLL/ $\alpha$-CAS) $)_{n}$ and (PLL/ $\beta$-CAS) ${ }_{n}$ after $24 \mathrm{~h}$ exposition to solutions of various $\mathrm{pH}$ (typical error of thickness measurements $\pm 1 \mathrm{~nm}$ )
Table 2 Ellipsometric thickness (in nanometers) of multilayer films $(\mathrm{PLL} / \alpha-\mathrm{CAS})_{n}$ and $(\mathrm{PLL} / \beta-\mathrm{CAS})_{n}$ after $24 \mathrm{~h}$ exposition to solutions of various composition (typical error of thickness measurements $\pm 1 \mathrm{~nm})$

\begin{tabular}{|c|c|c|c|c|c|c|}
\hline Film $\backslash$ solution & $\begin{array}{l}\text { Freshly } \\
\text { formed }\end{array}$ & pH 2 & $\mathrm{pH} 4$ & $\mathrm{pH} 7.4$ & pH 9 & pH 11 \\
\hline$(\mathrm{PLL} / \alpha-\mathrm{CAS})_{2} \mathrm{PLL}$ & 7 & 1 & 5 & 6 & 7 & 3 \\
\hline$(\mathrm{PLL} / \alpha-\mathrm{CAS})_{3}$ & 15 & 1 & 15 & 13 & 13 & 2 \\
\hline$(\mathrm{PLL} / \alpha-\mathrm{CAS})_{3} \mathrm{PLL}$ & 17 & 1 & 12 & 15 & 14 & 4 \\
\hline$(\mathrm{PLL} / \alpha-\mathrm{CAS})_{4}$ & 33 & 2 & 30 & 30 & 26 & 5 \\
\hline$(\mathrm{PLL} / \beta-\mathrm{CAS})_{2} \mathrm{PLL}$ & 3 & $<1$ & 2 & 3 & 2 & 2 \\
\hline$(\mathrm{PLL} / \beta-\mathrm{CAS})_{3}$ & 6 & $<1$ & 3 & 5 & 4 & 2 \\
\hline$(\mathrm{PLL} / \beta-\mathrm{CAS})_{3} \mathrm{PLL}$ & 6 & $<1$ & 3 & 6 & 5 & 3 \\
\hline$(\mathrm{PLL} / \beta-\mathrm{CAS})_{4}$ & 8 & $<1$ & 3 & 8 & 6 & 3 \\
\hline Film $\backslash$ solution & $\begin{array}{l}\text { Freshly } \\
\text { formed }\end{array}$ & $\mathrm{NaCl}$ & $\mathrm{CaCl}_{2}$ & \multicolumn{2}{|c|}{$\mathrm{Ca}_{3}\left(\mathrm{PO}_{4}\right)_{2}$} & HEPES \\
\hline$(\mathrm{PLL} / \alpha-\mathrm{CAS})_{3} \mathrm{PLL}$ & 17 & 12 & 10 & \multicolumn{2}{|c|}{13} & 14 \\
\hline$(\mathrm{PLL} / \alpha-\mathrm{CAS})_{4}$ & 33 & 30 & 14 & \multicolumn{2}{|c|}{26} & 32 \\
\hline$(\mathrm{PLL} / \beta-\mathrm{CAS})_{3} \mathrm{PLL}$ & 6 & 4 & 4 & \multicolumn{2}{|c|}{6} & 6 \\
\hline$(\mathrm{PLL} / \beta-\mathrm{CAS})_{4}$ & 8 & 6 & 6 & \multicolumn{2}{|c|}{9} & 9 \\
\hline
\end{tabular}

contributes to the stability of these films. In the same conditions $\beta$-casein containing films are less stable due to higher positive charge of the protein. In the neutral and weakly basic conditions, films containing both types of casein are stable (i.e., the observed decrease of thickness is less than c.a. $15 \%$ ), which is an important factor for the potential application of casein containing films for surface modification of materials used for dental implants. On the other hand $\mathrm{pH}$ driven degradation of the films can be utilized in the triggered release systems.

Multilayer films of the composition (PLL/ $\alpha-\mathrm{CAS})_{3} \mathrm{PLL}$, $(\mathrm{PLL} / \alpha-\mathrm{CAS})_{4}$ and $(\mathrm{PLL} / \beta-\mathrm{CAS})_{3} \mathrm{PLL}, \quad(\mathrm{PLL} / \beta-\mathrm{CAS})_{4}$ formed at the surface of silicon wafers from solutions of PLL and casein at $I=0.15 \mathrm{M} \mathrm{NaCl}$ (in HEPES), were selected for the investigation of their stability in $\mathrm{NaCl}, \mathrm{CaCl}_{2}$, $\mathrm{Ca}_{3}\left(\mathrm{PO}_{3}\right)_{2}$ solutions and HEPES buffer. Freshly formed films were exposed for 24 hours to the salt solutions, dried and their ellipsometric thickness was measured. The results are collected in Table 2. One can see that films containing both type of casein are stable in the HEPES buffer, which is widely used in cell culture since it maintains the physiological $\mathrm{pH}$ despite changes in carbon dioxide concentration. Stability of $\alpha$-casein containing films in $\mathrm{NaCl}$ is better than for ones with $\beta$-casein, due to higher negative charge of $\alpha$-casein (Dickinson 2006). In the presence of calcium chloride solution both types of casein films decrease their thickness due to screening of electric charges by divalent calcium ions, which are also bound to the casein embedded in the film as it was demonstrated in SzykWarszyńska et al. (2009). As the result of that binding the films can undergo structural changes, which can also contribute to a change of their thickness. The same phenomenon can be observed for $\alpha$-casein containing films when exposed to calcium phosphate solution. On the other hand films with $\beta$-casein are not sensitive to $\mathrm{Ca}_{3}\left(\mathrm{PO}_{4}\right)_{2}$, which is in agreement with the observation that this type of casein is less sensitive to calcium precipitation (Horne 2002).

We used fluorescent microscopy to determine whether changes of ellipsometric thickness of casein containing multilayer films after their exposure to solutions containing calcium ions are caused by film desorption or structural changes due to calcium binding. For that purpose we formed films containing PLL as polycation and fluorescently labeled casein $\left(\mathrm{CAS}^{*}\right)$ at the surface of silicon wafers. That allowed us to correlate the thickness of multilayer film determined by ellipsometry with fluorescence intensity, which should be proportional to the amount of adsorbed casein. The results are demonstrated in Fig. 2. One can observe the monotonous increase of the film thickness and fluorescent intensity with the number of (PLL/CAS ${ }^{*}$ ) bilayers. There exists a good correlation between ellipsometric thickness of the film and fluorescent intensity. The amount of casein deposited in one layer increases with the film thickness, as the first precursor layers of the film are very nonhomogeneous and contain less adsorbed protein. The PLL/CAS* multilayer films were contacted with the solutions of $\mathrm{Ca}_{3}\left(\mathrm{PO}_{4}\right)_{2}$ and $\mathrm{CaCl}_{2}$ and after drying, changes of film thickness and fluorescence intensity were monitored. The results are shown in Figs. 3 and 4. Comparing ellipsometric thickness and fluorescence 
Fig. 2 Dependence of the ellipsometric thickness and fluorescence intensity of $\left(\text { PLL/CAS }{ }^{*}\right)_{n}$ multilayer films formed at silicon wafers on the number of deposited bilayers

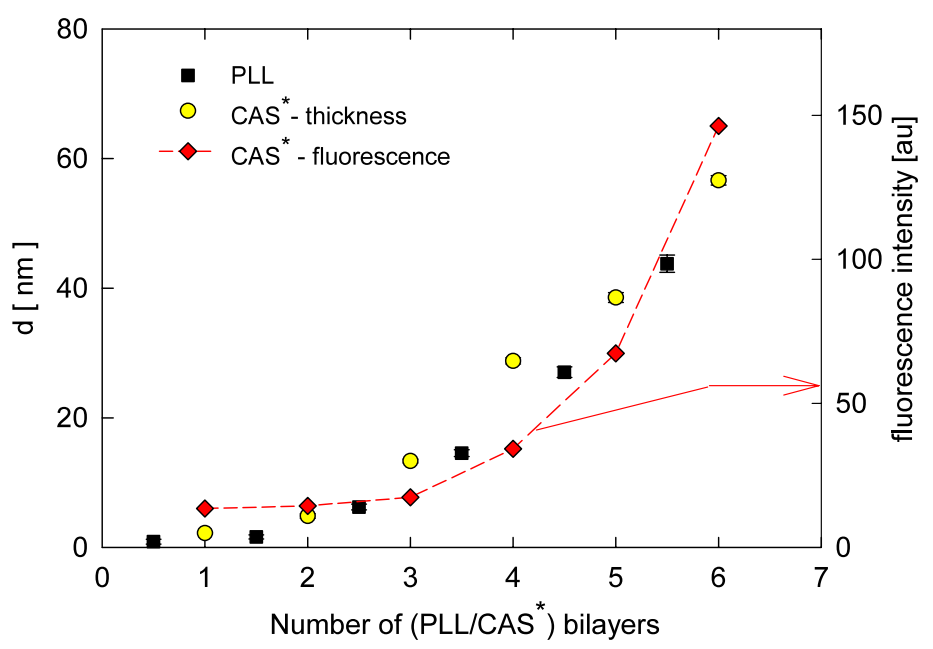

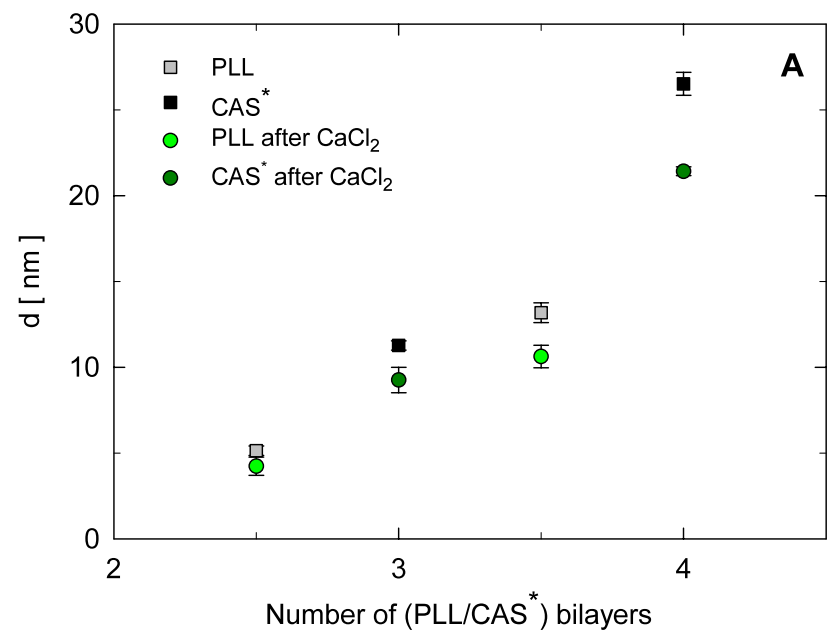

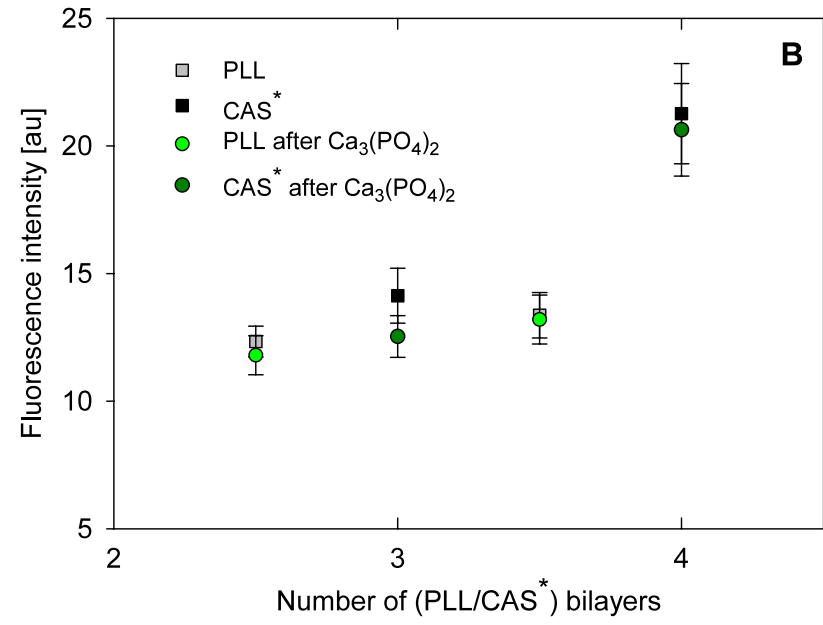

Fig. 3 Dependence of the ellipsometric thickness (A) and fluorescence intensity $(\mathbf{B})$ of $\left(\text { PLL/CAS }{ }^{*}\right)_{n}$ multilayer films formed at silicon wafers on the number of deposited bilayers before and after $24 \mathrm{~h}$ exposition to the solution of $0.15 \mathrm{M}$ of calcium phosphate

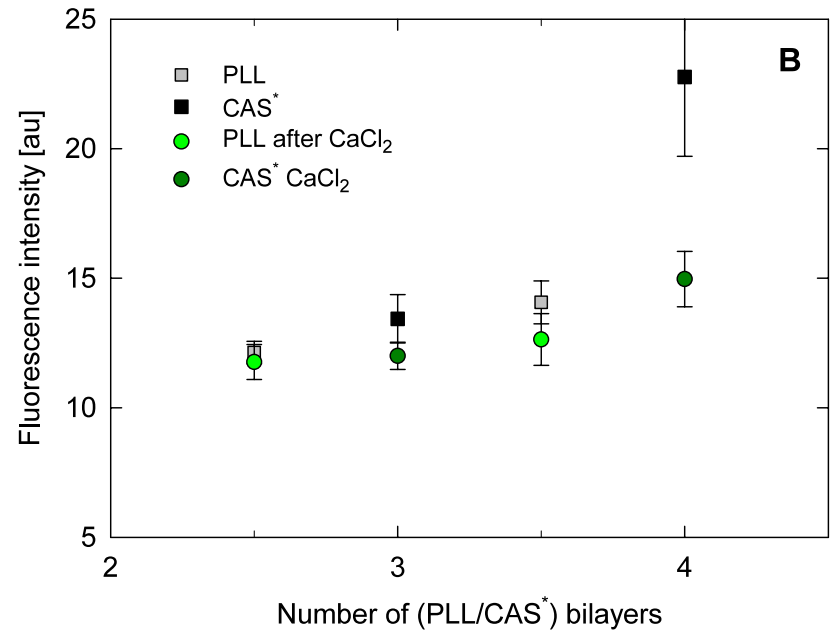

Fig. 4 Dependence of the ellipsometric thickness (A) and fluorescence intensity $(\mathbf{B})$ of $\left(\mathrm{PLL} / \mathrm{CAS}{ }^{*}\right)_{n}$ multilayer films formed at silicon wafers on the number of deposited bilayers before and after $24 \mathrm{~h}$ exposition to the solution of $0.15 \mathrm{M}$ of calcium chloride 


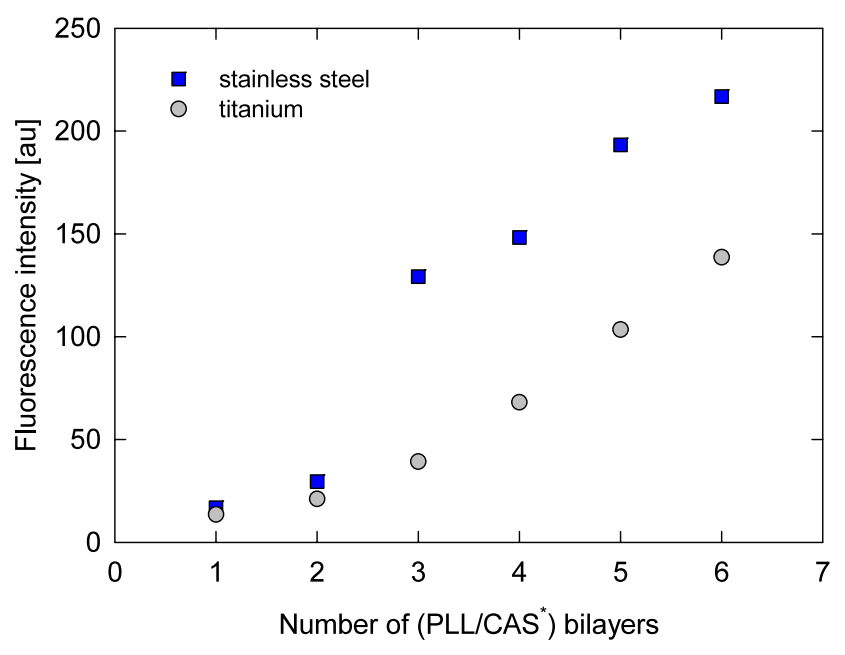

Fig. 5 Dependence of the fluorescence intensity of (PLL/CAS $\left.{ }^{*}\right)_{n}$ multilayer films formed at stainless steel and titanium on the number of deposited bilayers

intensity of (PLL/CAS ${ }^{*}$ ) multilayer films before and after 24 hours exposition to solutions of calcium ions one can conclude that a small decrease of thickness of films after treatment with $\mathrm{Ca}_{3}\left(\mathrm{PO}_{4}\right)_{2}$ is practically not accompanied by the decrease of film fluorescence intensity. It means that casein was not desorbed. On the other hand, after treatment of films with $\mathrm{CaCl}_{2}$ the decrease of their thickness correlates with reduction of film fluorescence intensity, which is an evidence of partial desorption of casein.

We demonstrated in Trybała et al. (2009) that fluorescent microscopy is a convenient tool to study formation of multilayer films at non-homogeneous, metallic surfaces where ellipsometric measurements are impossible. Therefore, we used fluorescent casein to form PLL/casein multilayer films at surfaces of titanium and stainless steel, which are materials used for production of implants or vessels in dairy industry. We followed the growth of the film by monitoring increase of fluorescence. The results are shown in Fig. 5. It can be seen that films are formed at both metallic surfaces as it is evidenced by monotonic increase of fluorescence with number of deposited (PLL/casein) bilayers. Fluorescence intensity of PLL/casein films is higher at the steel surface than titanium, which is the result of larger surface roughness of steel plates (Trybała et al. 2009).

Multilayer films of the composition (PLL $/ \alpha-\mathrm{CAS})_{3}$ PLL, $(\mathrm{PLL} / \alpha-\mathrm{CAS})_{4}$ and $(\mathrm{PLL} / \beta-\mathrm{CAS})_{3} \mathrm{PLL}, \quad(\mathrm{PLL} / \beta-\mathrm{CAS})_{4}$ were selected for the investigation of the response of their thickness to the changes of temperature, according to the procedure described in the "Materials and Methods" section. The results of our experiments are collected in Figs. 6 and 7 , where the relative change of ellipsometric thickness, $d(T)$, with respect to the initial thickness at $20^{\circ} \mathrm{C}$.

$\Delta d=\left(\frac{d(T)-d\left(20^{\circ} \mathrm{C}\right)}{d\left(20^{\circ} \mathrm{C}\right)}\right)$
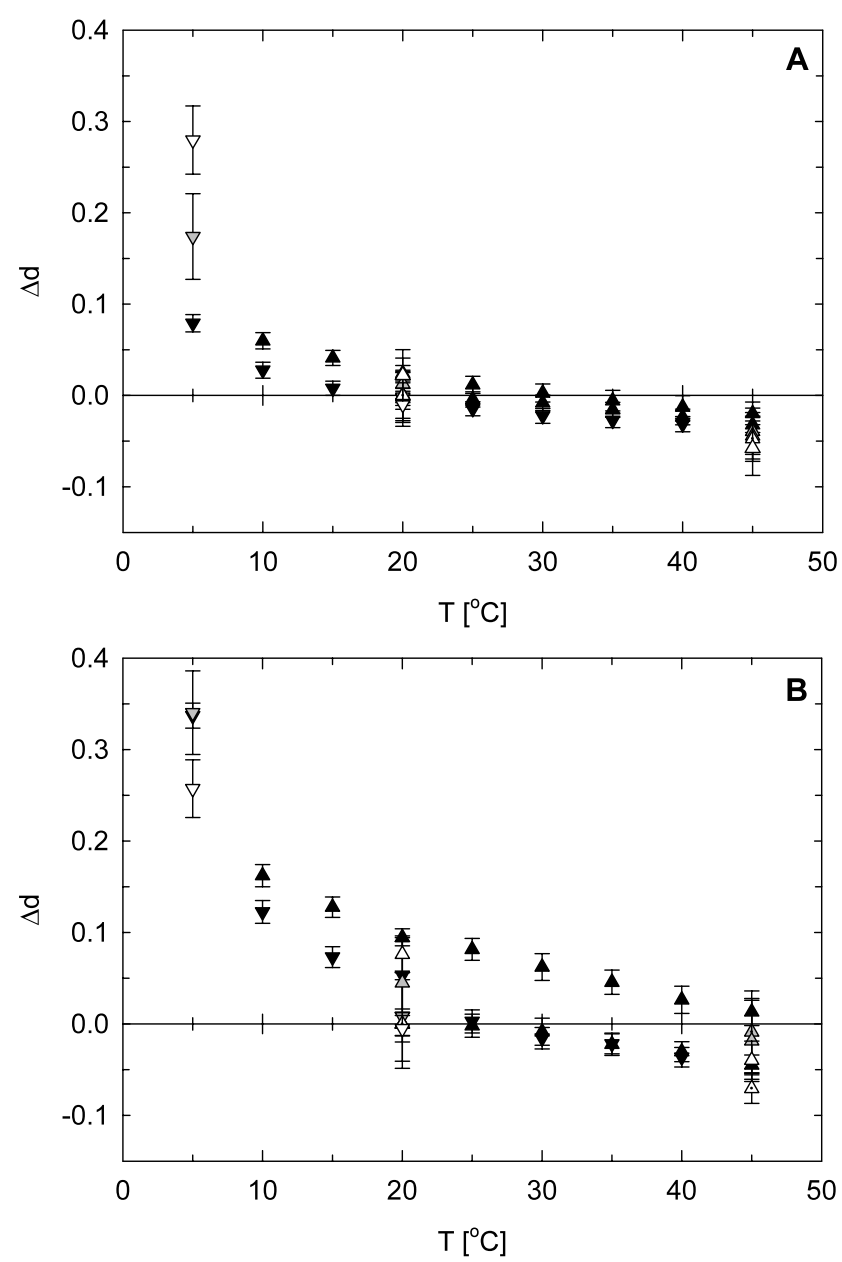

Fig. 6 Dependence of the relative change of ellipsometric thickness on the temperature for (A) (PLL/ $\alpha$-CAS) $)_{3}$ PLL and (B) $(\mathrm{PLL} / \beta \text {-CAS })_{3} \mathrm{PLL}$ films. Triangle up: increasing temperature; triangle down: decreasing temperature; black symbols: untreated films; white symbols: films treated with $\mathrm{CaCl}_{2}$; gray symbols: $\mathrm{Ca}_{3}\left(\mathrm{PO}_{4}\right)_{2}$

is shown as a function of temperature. It can be seen that major changes of film thickness occur, when the films are cooled down to $5{ }^{\circ} \mathrm{C}$. It is most probably connected with sorption of water vapor in the film. On the other hand changes of the film thickness upon heating are negligible. One can observe, at low temperatures, larger swelling (20$30 \%$ ) of $\beta$-casein containing films than that of the films with $\alpha$-casein. Thickness of the films with $\beta$-casein also exhibits some temperature hysteresis connected with kinetics of water vapor sorption. Exposure of the films to calcium salt solutions for 24 hours increased their hygroscopicity as it was demonstrated by larger relative increase of film thickness at $5{ }^{\circ} \mathrm{C}$, especially significant for $\alpha$-casein films. Since calcium salts are hygroscopic, e.g. $\mathrm{CaCl}_{2}$ is frequently used as a drying agent, their presence in the PLL/casein multilayer films contributes to higher sorption of water vapor and larger swelling of the films. 

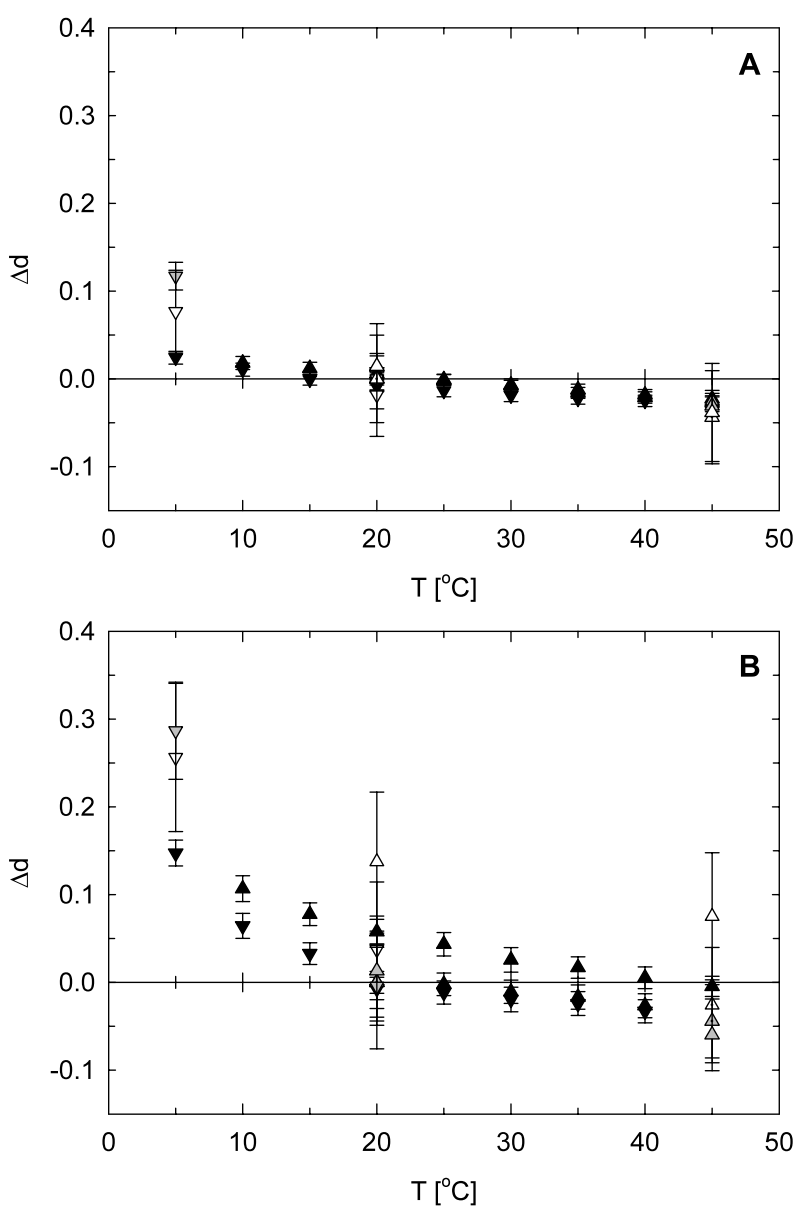

Fig. 7 Dependence of the relative change of ellipsometric thickness on the temperature for (A) $(\mathrm{PLL} / \alpha-\mathrm{CAS})_{4}$ and (B) $(\mathrm{PLL} / \beta \text {-CAS })_{4}$ films. Meaning of the symbols the same as in Fig. 6

\section{Conclusions}

We investigated formation of polyelectrolyte multilayer films containing $\alpha$ - and $\beta$-casein. Films were formed at surface of silicon wafers, titanium and stainless steel plates by layer-by-layer adsorption. Casein was used as a polyanionic layer for the film build-up together with polycation, polyL-lysine. Investigating by ellipsometry the dependence of the thickness of casein containing multilayer films on the ionic strength of the polyelectrolyte and casein solution, we found that the optimal conditions for film formation occurs at $I=0.15 \mathrm{M} \mathrm{NaCl}$. Films deposited at surface of silicon wafers were not resistant to solutions of $\mathrm{pH} 2$ due to charge reversal of casein and $\mathrm{pH} 11$ due to neutralization of PLL. Close the isoelectric point of casein- $\mathrm{pH} 4$, only films containing $\alpha$-casein were stable. In neutral and weakly basic conditions films containing both types of casein were stable. They were also stable in the HEPES buffer, which is widely used in cell culture and biomedical experiments. Stability of $\alpha$-casein containing films in $\mathrm{NaCl}$ is better than for ones with $\beta$-casein, due to higher negative charge of $\alpha$-casein. In the presence of calcium chloride and calcium phosphate the decrease of film thickness is observed. That decrease can be a result of screening of electrostatic interactions between casein and polycation by multivalent ions as well as structural changes occurring in the film, as a consequence of calcium binding by embedded casein. Increased hygroscopicity of films after the contact with solution of calcium salts also indicate their binding by casein containing polyelectrolyte multilayers. Stable PLL/casein film can be also obtained at nonhomogeneous surfaces of titanium and stainless steel, which are materials used for production of implants or vessels in diary industry.

Acknowledgement This work was partially financed by ECO-Net project and by grant of MNiSW.

Open Access This article is distributed under the terms of the Creative Commons Attribution Noncommercial License which permits any noncommercial use, distribution, and reproduction in any medium, provided the original author(s) and source are credited.

\section{References}

Alaimo, M.H., Wickham, E.D., Farell, H.M. Jr.: Biochim. Biophys. Acta 1431, 395-409 (1999)

Brighta, J.N., Woolf, T.B., Hoh, J.H.: Prog. Biophys. Mol. Biol. 76, 131-173 (2001)

Buron, C.C., Filiâtre, C., Membrey, F., Perrot, H., Foissy, A.: J. Colloid Interface Sci. 296, 409 (2006)

Castelnovo, M., Joanny, J.-F.: Langmuir 16, 7524 (2000)

Decher, G.: Science 277, 232 (1997)

Decher, G., Hong, J.-D.: Ber. Bunsen.-Ges. Phys. Chem. 95, 1430 (1991)

Dickinson, E.: Colloids Surfaces A 288, 3-11 (2006)

Dyson, H.J., Wright, P.E.: Curr. Opin. Struct. Biol. 12, 54-60 (2002)

Elzbieciak, M., Zapotoczny, S., Nowak, P., Krastev, R., Nowakowska, M., Warszynski, P.: Langmuir 25, 3255-3259 (2009)

Furedi-Milhofer, H., Sikiric, M., Yosef, P.B., Cuisinier, F.J.G., Gergely, Cs.: US patent application \#60-428.725 (2004)

Hammond, P.T.: Curr. Opin. Colloid Interface Sci. 4, 430 (2000)

Horne, D.S.: Curr. Opin. Colloid Interface Sci. 7, 456-461 (2002)

Keddie, J.L.: Curr. Opin. Colloid Interface Sci. 6, 102-110 (2001)

Kolasińska, M., Krastev, R., Warszyński, P.: J. Colloid Interface Sci. 305, 46-56 (2007)

Kosmulski, M.: Chemical Properties of Material Surfaces. Dekker, New York (2001)

Maheshwari, R.K., Singh, A.K., Gaddipati, J., Srimal, R.C.: Life Sci. 78, 2081-2087 (2006)

Maldonado-Valderrama, J., Martın-Molina, A., Galvez-Ruiz, M.J., Martın-Rodrıguez, A., Cabrerizo-Vılchez, M.A.: J. Phys. Chem. B 108, 12940-12945 (2004)

Maldonado-Valderrama, J., Martin-Rodriguez, A., Galvez-Ruiz, M.J., Miller, R., Langevin, D., Cabrerizo-Vilchez, M.A.: Colloids Surfaces A 323, 116-122 (2008)

Miller, R., Fainerman, V.B., Leser, M.E., Michel, M.: Curr. Opin. Colloids Interface Sci. 9, 350-356 (2004)

Mishra, S.P., Tiwari, D., Dubey, R.S., Mishra, M.: Bioresour. Technol. 63, 1-5 (1998)

Muller-Buschbaum, P., Gebhardt, R., Maurer, E., Bauer, E., Gehrke, R., Doster, W.: Biomacromolecules 7, 1773-1789 (2006)

Qi, P.X., Wickham, E.D., Farell, H.M. Jr.: Protein J. 23, 389-402 (2004) 
Schönhoff, M.: Curr. Opin. Colloid Interface Sci. 8, 86 (2003)

Seki, H., Suzuki, A.: J. Colloid Interface Sci. 249, 295-300 (2002)

Smyth, E., Clegg, R.A., Holt, C.: Int. J. Dairy Technol. 57(2-3), 121$126(2004)$

Swaisgood, H.E.: Chemistry of the caseins. In: Fox P.F. (ed.) Advanced Diary Chemistry, Proteins, pp. 63-110. Elsevier, New York (1992)

Szyk-Warszyńska, L., Gergely, C., Jarek, E., Cuisinier, F., Socha, R.P., Warszyński, P.: Colloids Surfaces A 343, 118-126 (2009)
Tang, Z., Wang, Y., Podsiadlo, P., Kotov, N.A.: Adv. Mater. 18, 3203 3224 (2006)

Tompa, P.: Intrinsically unstructured proteins. TRENDS Biochem. Sci. 27, 527-533 (2002)

Tompkins, H.G., Irene, E.A.: Handbook of Ellipsometry. Springer, Berlin (1999)

Trybała, A., Szyk-Warszyńska, L., Warszyński, P.: Colloid Interface Sci. A 343, 127-132 (2009)

Wright, P.E., Dyson, H.J.: J. Mol. Biol. 293, 321-331 (1999) 